\title{
Ideal of Prime $\Gamma$-Rings with Right Reverse Derivations
}

\author{
Salah Mehdi Salih and Marwa Riyadh Salih \\ Al-Mustansirya University College of Education \\ Department of Mathematics
}

\begin{abstract}
In this paper some results concerning to right reverse derivation on prime $\Gamma$-rings are presented if $M$ be a prime $\Gamma$-ring with non-zero right reverse derivation $d$ and $U$ be the ideal of $M$, then $M$ is commutative.

Mathematics Subject Classification: 16A70, 16N60, $16 \mathrm{~W} 25$

Keywords: prime $\Gamma$-ring, derivation, reverse derivation.
\end{abstract}

\section{Introduction:}

The concepts of a $\Gamma$-ring was first by Nodusawa [5] in 1964. Now a day his $\Gamma$-ring is called a $\Gamma$-ring in the sense of Nobusawa this $\Gamma$-ring is generalized by W.E.Barnes [1] in a broad sense that served now- a day to call $\Gamma$-ring

Let $\mathrm{M}$ and $\Gamma$ be additive abelian groups, if there exists a mapping $\mathrm{M} \times \Gamma \mathrm{x} \mathrm{M} \rightarrow \mathrm{M}:(\mathrm{x}, \alpha, \mathrm{y}) \rightarrow \mathrm{x} \alpha \mathrm{y}$ which satisfies the following conditions, for all $\mathrm{a}, \mathrm{b}, \mathrm{c} \in \mathrm{M}$ and $\alpha, \beta \in \Gamma$ :

$$
\text { 1. } \begin{aligned}
(a+b) \alpha c & =a \alpha c+b \alpha c \\
a(\alpha+\beta) b & =a \alpha b+a \beta b \\
a \alpha(b+c) & =a \alpha b+a \alpha c
\end{aligned}
$$

2. $(a \alpha b) \beta c=a \alpha(b \beta c)$

Then $\mathrm{M}$ is called a $\Gamma$-ring. [1]

We writ $[x, y]_{\alpha}$ for $\mathrm{x} \alpha \mathrm{y}-\mathrm{y} \alpha \mathrm{x}$. Recall that a $\Gamma$-ring $\mathrm{M}$ is called prime if $\mathrm{a} \Gamma \mathrm{M} \Gamma \mathrm{b}=0$ implies $\mathrm{a}=0$ or $\mathrm{b}=0$ and it is called semiprime if $\mathrm{a} \Gamma \mathrm{M} \Gamma \mathrm{a}=0$ implies $\mathrm{a}=0$, $\mathrm{a} \Gamma$-ring $\mathrm{M}$ is called commutative if $[x, y]_{\alpha}=0$ for all $\mathrm{x}, \mathrm{y} \in \mathrm{M}$ and $\alpha \in \Gamma$,Bresar and Vakman [2] have introduced the notion of a reverse derivation, the reverse derivation on semi prime rings have been studied by Samman and Alyamani [6] and K.KDey, A.IC.Paul, I.S.Rakhimov [3] have introduced the concepts of reverse derivation on $\Gamma$-ring as an additive mapping $\mathrm{d}$ from $\mathrm{M}$ in to $M$ is called reverse derivation if $d(x \alpha y)=d(y) \alpha x+y \alpha d(x)$, for all $x, y \in M, \alpha \in \Gamma$ and we consider an assumption (*) by $x \alpha y \beta z=x \alpha y \beta z$ for all $x, y, z \in U, \alpha, \beta \in \Gamma$, where $U$ is ideal of $\Gamma$-ring.

Taking the above as assumption (*) the basic commutate identities reduce to $[x \beta y, z]_{\alpha}=x \beta[y, z]_{\alpha}+[x, z]_{\alpha} \beta y$ and $[x, y \beta z]_{\alpha}=y \beta[x, z]_{\alpha}+[x, y]_{\alpha} \beta z$ for all $\mathrm{x}, \mathrm{y}, \mathrm{z} \in \mathrm{U}$ and for all $\alpha, \beta \in \Gamma$ which are used extensively in our results

C.J.S.Reddy and K.Hemavathi [4] studied the right reverse derivation on prim ring and we extend in this paper the results mentioned above to prime $\Gamma$-rings case

\section{The Main Results:}

In this section we introduce the main results of this paper we begin with the following theorem:

Theorem(1): Let $M$ be a prime $\Gamma$-ring, $U$ a non zero ideal of $M$ and $d$ be a right reverse derivation of $M$, if $U$ is non-commutative such that $(*)$ for all $\mathrm{x}, \mathrm{y}, \mathrm{z} \in \mathrm{U}$ And $\alpha, \beta \in \Gamma$, then $\mathrm{d}=0$.

Proof:

Since $d$ is right reverse derivation and since $(*)$ then

Let $d(x \alpha x \beta y)=d(y) \beta x \alpha x+d(x) \alpha x \beta y+d(x) \alpha x \beta y$

On the other hand

$$
=d(y) \beta x \alpha x+d(x) \beta x \alpha y+d(x) \alpha x \beta y \ldots . .(1)
$$

$\mathrm{d}(\mathrm{x} \alpha \mathrm{x} \beta \mathrm{y})=\mathrm{d}(\mathrm{x} \alpha(\mathrm{x} \beta \mathrm{y}))$

$=\mathrm{d}(\mathrm{x} \beta \mathrm{y}) \alpha \mathrm{x}+\mathrm{d}(\mathrm{x}) \alpha \mathrm{x} \beta \mathrm{y}$

$=\mathrm{d}(\mathrm{y}) \beta \mathrm{x} \alpha \mathrm{x}+\mathrm{d}(\mathrm{x}) \beta \mathrm{y} \alpha \mathrm{x}+\mathrm{d}(\mathrm{x}) \alpha \mathrm{x} \beta \mathrm{y}$

Compare (1) and (2) we get

$\mathrm{d}(\mathrm{x}) \beta \mathrm{y} \alpha \mathrm{x}=\mathrm{d}(\mathrm{x}) \beta \mathrm{x} \alpha \mathrm{y}$

$\Rightarrow \mathrm{d}(\mathrm{x}) \beta \mathrm{y} \alpha \mathrm{x}-\mathrm{d}(\mathrm{x}) \beta \mathrm{x} \alpha \mathrm{y}=0$

$\Rightarrow \mathrm{d}(\mathrm{x}) \beta(\mathrm{y} \alpha \mathrm{x}-\mathrm{x} \alpha \mathrm{y})=0$

$\Rightarrow \mathrm{d}(\mathrm{x}) \beta[y, x]_{\alpha}=0$ for all $\mathrm{x}, \mathrm{y} \in \mathrm{U}, \alpha, \beta \in \Gamma$. 
We replace y by y $\beta z$ in equation (3) and using (3) we get :

$\mathrm{d}(\mathrm{x}) \beta[y \beta z, x]_{\alpha}=0$ for all $\mathrm{x}, \mathrm{y}, \mathrm{z} \in \mathrm{U}$ and $\alpha, \beta \in \Gamma$

$\Rightarrow \mathrm{d}(\mathrm{x}) \beta \mathrm{y} \beta[z, x]_{\alpha}+\mathrm{d}(\mathrm{x}) \beta[y, x]_{\alpha} \beta \mathrm{z}=0$

$\Rightarrow \mathrm{d}(\mathrm{x}) \beta \mathrm{y} \beta[z, x]_{\alpha}=0$ for all $\mathrm{x}, \mathrm{y}, \mathrm{z} \in \mathrm{U}$ and $\alpha, \beta \in \Gamma$

By writing $\mathrm{y}$ by $\mathrm{y} \alpha \mathrm{m}, \mathrm{m} \in \mathrm{M}$ in equation (4) we obtain

$\Rightarrow \mathrm{d}(\mathrm{x}) \beta \mathrm{y} \alpha \mathrm{m} \beta[z, x]_{\alpha}=0$ for all $\mathrm{x}, \mathrm{y}, \mathrm{z} \in \mathrm{U}$ and $\alpha, \beta \in \Gamma, \mathrm{m} \in \mathrm{M}$

If we interchange $\mathrm{m}$ and $\mathrm{y}$, then we get

$\Rightarrow \mathrm{d}(\mathrm{x}) \beta \operatorname{m\alpha y} \beta[z, x]_{\alpha}=0$ for all $\mathrm{x}, \mathrm{y}, \mathrm{z} \in \mathrm{U}, \mathrm{m} \in \mathrm{M}$ and $\alpha, \beta \in \Gamma$

By primness property, either $\mathrm{d}(\mathrm{x})=0$ (or) $[z, x]_{\alpha}=0$

Since $\mathrm{U}$ is non-commutative, then $\mathrm{d}=0$.

Theorem(2): Let $\mathrm{M}$ be a prime $\Gamma$-ring, $\mathrm{U}$ is ideal of $\mathrm{M}$ and $\mathrm{d}$ be a non-zero right reverse derivation of $\mathrm{M}$. if $[d(y), d(x)]_{\alpha}=[y, x]_{\alpha}$ such that $(*)$ for all $\mathrm{x}, \mathrm{y}, \mathrm{z} \in \mathrm{U}$ and $\alpha, \beta \in \Gamma$, then $[x, d(x)]_{\alpha}=0$ and hence $\mathrm{M}$ is commutative.

Proof:

Gavin that $[d(y), d(x)]_{\alpha}=[y, x]_{\alpha}$ for all $\mathrm{x}, \mathrm{y} \in \mathrm{U}, \alpha \in \Gamma$

By taking $\mathrm{y} \beta \mathrm{x}$ instead of $\mathrm{y}$ in the hypothesis, then we get

$[y \beta x, x]_{\alpha}=[d(y \beta x), d(x)]_{\alpha}$

$\Rightarrow \mathrm{y} \beta[x, x]_{\alpha}+[y, x]_{\alpha} \mathrm{x}=[d(x) \beta y+d(y) \beta x, d(x)]_{\alpha}$

$\Rightarrow[y, x]_{\alpha} \beta \mathrm{x}=(\mathrm{d}(\mathrm{x}) \beta \mathrm{y}+\mathrm{d}(\mathrm{y}) \beta \mathrm{x}) \alpha \mathrm{d}(\mathrm{x})-\mathrm{d}(\mathrm{x}) \alpha(\mathrm{d}(\mathrm{x}) \beta \mathrm{y}+\mathrm{d}(\mathrm{y}) \beta \mathrm{x})$

$\Rightarrow[y, x]_{\alpha} \beta \mathrm{x}=\mathrm{d}(\mathrm{x}) \beta \mathrm{y} \alpha \mathrm{d}(\mathrm{x})+\mathrm{d}(\mathrm{y}) \beta \mathrm{x} \alpha \mathrm{d}(\mathrm{x})-\mathrm{d}(\mathrm{x}) \alpha \mathrm{d}(\mathrm{x}) \beta \mathrm{y}-\mathrm{d}(\mathrm{x}) \alpha \mathrm{d}(\mathrm{y}) \beta \mathrm{x}$

Adding and subtracting $\mathrm{d}(\mathrm{y}) \beta \mathrm{d}(\mathrm{x}) \alpha \mathrm{x}$

$\Rightarrow[y, x]_{\alpha} \beta \mathrm{x}=\mathrm{d}(\mathrm{x}) \beta \mathrm{y} \alpha \mathrm{d}(\mathrm{x})+\mathrm{d}(\mathrm{y}) \beta \mathrm{x} \alpha \mathrm{d}(\mathrm{x})-\mathrm{d}(\mathrm{x}) \alpha \mathrm{d}(\mathrm{x}) \beta \mathrm{y}-\mathrm{d}(\mathrm{x}) \alpha \mathrm{d}(\mathrm{y}) \beta \mathrm{x}+\mathrm{d}(\mathrm{y}) \beta \mathrm{d}(\mathrm{x}) \alpha \mathrm{x}-\mathrm{d}(\mathrm{y}) \beta \mathrm{d}(\mathrm{x}) \alpha \mathrm{x}$

$\Rightarrow[y, x]_{\alpha} \beta \mathrm{x}=\mathrm{d}(\mathrm{x}) \beta \mathrm{y} \alpha \mathrm{d}(\mathrm{x})+\mathrm{d}(\mathrm{y}) \beta \mathrm{x} \alpha \mathrm{d}(\mathrm{x})-\mathrm{d}(\mathrm{x}) \beta \mathrm{d}(\mathrm{x}) \alpha \mathrm{y}-\mathrm{d}(\mathrm{x}) \alpha \mathrm{d}(\mathrm{y}) \beta \mathrm{x}+\mathrm{d}(\mathrm{y}) \alpha \mathrm{d}(\mathrm{x}) \beta \mathrm{x}-\mathrm{d}(\mathrm{y}) \beta \mathrm{d}(\mathrm{x}) \alpha \mathrm{x}$

$\Rightarrow[y, x]_{\alpha}=\mathrm{d}(\mathrm{x}) \beta \mathrm{y} \alpha \mathrm{d}(\mathrm{x})-\mathrm{d}(\mathrm{x}) \beta \mathrm{d}(\mathrm{x}) \alpha \mathrm{y}+\mathrm{d}(\mathrm{y}) \beta \mathrm{x} \alpha \mathrm{d}(\mathrm{x})-\mathrm{d}(\mathrm{y}) \beta \mathrm{x} \alpha \mathrm{d}(\mathrm{x})+\mathrm{d}(\mathrm{y}) \alpha \mathrm{d}(\mathrm{x}) \beta \mathrm{x}-\mathrm{d}(\mathrm{x}) \alpha \mathrm{d}(\mathrm{y}) \beta \mathrm{x}$

$\Rightarrow[y, x]_{\alpha} \beta \mathrm{x}=\mathrm{d}(\mathrm{x}) \beta[y, d(x)]_{\alpha}+\mathrm{d}(\mathrm{y}) \beta[x, d(x)]_{\alpha}+[d(y), d(x)]_{\alpha} \beta \mathrm{x}$

$\Rightarrow \mathrm{d}(\mathrm{x}) \beta[y, d(x)]_{\alpha}+\mathrm{d}(\mathrm{y}) \beta[x, d(x)]_{\alpha}=0 \ldots . .(5)$

Replace y by cay where $\mathrm{c} \in \mathrm{Z}(\mathrm{M})$ and using equation (5) we get,

$\Rightarrow \mathrm{d}(\mathrm{x}) \beta[y, x]_{\alpha}+\mathrm{d}(\mathrm{c} \alpha \mathrm{y}) \beta[x, d(x)]_{\alpha}=0$

$\Rightarrow \mathrm{d}(\mathrm{x}) \beta\left(\mathrm{c} \alpha[y, d(x)]_{\alpha}+[c, d(x)]_{\alpha} \alpha \mathrm{y}\right)+(\mathrm{d}(\mathrm{y}) \alpha \mathrm{c}+\mathrm{d}(\mathrm{c}) \alpha \mathrm{y}) \beta[x, d(x)]_{\alpha}=0$

$\Rightarrow \operatorname{cod}(\mathrm{x}) \beta[y, d(x)]_{\alpha}+[\mathrm{d}(\mathrm{x}) \beta c, d(x)]_{\alpha} \alpha \mathrm{y}+\operatorname{cod}(\mathrm{y}) \beta[x, d(x)]_{\alpha}$

$+\mathrm{d}(\mathrm{c}) \operatorname{\alpha y} \beta[x, d(x)]_{\alpha}=0$

$\left.\Rightarrow-\operatorname{cod}(\mathrm{y}) \beta[x, d(x)]_{\alpha}+\mathrm{d}(\mathrm{x}) \beta c, d(x)\right]_{\alpha} \alpha \mathrm{y}+\operatorname{c\alpha d}(\mathrm{y}) \beta[x, d(x)]_{\alpha}+\mathrm{d}(\mathrm{c}) \alpha \mathrm{y} \beta[x, d(x)]_{\alpha}=0$

$\Rightarrow \mathrm{d}(\mathrm{c}) \alpha \mathrm{y} \beta[x, d(x)]_{\alpha}=0$ for all $\mathrm{x}, \mathrm{y} \in \mathrm{U}$ and $\alpha, \beta \in \Gamma$

Since $0 \neq \mathrm{d}(\mathrm{c}) \in \mathrm{Z}(\mathrm{M})$ and $\mathrm{U}$ is ideal of $\mathrm{M}$, then we have $[x, d(x)]_{\alpha}=0$ for all $\mathrm{x} \in \mathrm{U}$

By using the similar procedure as in theorem (1) then we get either $\mathrm{d}(\mathrm{x})=0$ (or) $[z, x]_{\alpha}=0$

Since $\mathrm{d}$ is non-zero, then $[z, x]_{\alpha}=0$

Hence $\mathrm{M}$ is commutative.

Theorem (3): Let $\mathrm{M}$ be a prime $\Gamma$-ring, $\mathrm{U}$ is ideal of $\mathrm{M}$ and $\mathrm{d}$ be a non-zero right reverse derivation of $\mathrm{M}$. if $[d(y), d(x)]_{\alpha}=0$ for all $\mathrm{x}, \mathrm{y} \in \mathrm{U}, \alpha, \beta \in \Gamma$, then $\mathrm{M}$ is commutative.

Proof:

Given that $[d(y), d(x)]_{\alpha}=0$ for all $\mathrm{x}, \mathrm{y} \in \mathrm{U}$ and $\alpha \in \Gamma$

By taking $\mathrm{y} \beta \mathrm{x}$ instead of $\mathrm{y}$ in the hypothesis, then we get,

$\Rightarrow[d(y \beta x), d(x)]_{\alpha}=0$ for all $\mathrm{x}, \mathrm{y} \in \mathrm{U}$ and $\alpha, \beta \in \Gamma$

$\Rightarrow[d(x) \beta y+d(y) \beta x, d(x)]_{\alpha}=0$

$\Rightarrow[d(x) \beta y, d(x)]_{\alpha}+[d(y) \beta x, d(x)]_{\alpha}=0$

$\Rightarrow d(x) \beta[y, d(x)]_{\alpha}+[d(x), d(x)]_{\alpha} \beta y+d(y) \beta[x, d(x)]_{\alpha}+[d(y), d(x)]_{\alpha} \beta x=0$

$\Rightarrow \mathrm{d}(\mathrm{x}) \beta[y, d(x)]_{\alpha}+\mathrm{d}(\mathrm{y}) \beta[x, d(x)]_{\alpha}=0$

The proof is now completed by using equation (5) of theorem (2).

Hence $\mathrm{M}$ is commutative. 


\section{References}

[1] W.E.Barnes, 1966, "on the gamma rings of Nobusawa “,pacific .J. math 18, 411-422.

[2] M.Bresar and J.Vukman , on some additive mapping in rings with involution, equation math, 38(1989), 178 -185.

[3] K.K.Dey ,A.C.Paul, I.S.Rakhimove "Semiprim Gamma Rings With Orthogonal Reverse Derivations", International Journal Of Pure and Applied Mathematics, vol.83, No.2, 2013, 233-245.

[4] C.J.S.Reddy and K.Hemavathi, "right reverse derivation on prime rings", International Journal of Research in Engineering and Tec , vol.2, Issue 3, 2014, 141-144.

[5] N.Nobusawa, 1964, "on a generalization of the ring theory " Osaka J. Math.1, 81-89.

[6] M.Samman and N.Alyamani, "Derivation and reverse derivations in semiprim rings", International Mathematical forum2, No.39, (2007), 1895-1902. 